\title{
Nutritional and Metabolic Profile in Diabetic Patients and Relationship with Metabolic Syndrome
}

\author{
Djahida Hadj Merabet ${ }^{1 *}$, Karima Bereksi Reguig2 \\ ${ }^{1}$ Department of Biology, Faculty of Natural and Life Sciences, Djillali Liabes University, Sidi Bel Abbes, Algeria \\ ${ }^{2}$ Laboratory of Environment, Department of Biology, Faculty of Natural and Life Sciences, Djillali Liabes \\ University, Sidi Bel Abbes, Algeria \\ Email: "hmerabetd@hotmail.fr
}

Received 1 November 2015; accepted 18 March 2016; published 21 March 2016

Copyright (C) 2016 by authors and Scientific Research Publishing Inc.

This work is licensed under the Creative Commons Attribution International License (CC BY). http://creativecommons.org/licenses/by/4.0/

(c) (i) Open Access

\section{Abstract}

Background \& Objectives: Diabetes and metabolic syndrome spread alarmingly throughout the whole world including Algeria, so our study makes the links closer between these two entities and that through studying nutritional, metabolic and physical profiles. Study Design: 204 patients were recruited and interviewed (anthropometric measurements, blood pressure, age, sex, personal and family history, the practice of physical activity and evaluation of food consumption). Patients and Methods: A cross-sectional survey was conducted in the western Algerian region (Sidi Bel Abbes). Patients with MetS are defined according to the criteria of the National Cholesterol Education Program Adult Treatment Panel III (NCEP ATP III). Results: The results show that the frequency of the metabolic syndrome is $86.27 \%$ with predominance of women $(92.15 \%$ women vs $\mathbf{8 0 . 3 9 \%}$ men). The age group most affected by the MetS among women and men is [54 - 79] years. We also note that $51.28 \%$ of men present three criteria of MetS, while $65.21 \%$ of women have four and five criteria. The results show that the criteria most dominant in men are hypertension and type 2 diabetes, whereas in women, the high waist is the most abundant criterion. Moreover, the whole is underlined by a low physical activity with only $21.56 \%$ who practice it regularly $(15.95 \%$ women vs $28.04 \%$ men). The estimate of food intake shows a qualitative imbalance: protein intake is $19.65 \%$ in women vs. $19.43 \%$ in men represented mainly by vegetable protein $(83.72 \%$ for women vs. $72.85 \%$ for men); lipids intake is characterized by a lower consumption than the recommendation of the Mediterranean diet concerning the mono-unsaturated fatty acids (MUFA) (39.44\% among women vs $\mathbf{4 0 . 2 4 \%}$ at the men), as in poly unsaturated fatty-acids including (PUFA) (23.30\% among women vs $23.64 \%$ at the men) whereas an increase in the consumption of the saturated fatty-acids (SFA) is observed in the whole population including (37.24\% among women vs $\mathbf{3 6 . 1 0} \%$ at the men); lower concentration in calcium, magnesium and en fibers; important concen-

\footnotetext{
${ }^{*}$ Corresponding author.
}

How to cite this paper: Hadj Merabet, D. and Bereksi Reguig, K. (2016) Nutritional and Metabolic Profile in Diabetic Patients and Relationship with Metabolic Syndrome. Food and Nutrition Sciences, 7, 155-162. 
tration of sodium and an insufficient contribution of water. Conclusion: We should be aware of the importance of the modulation of these risk factors through harmonization of "lifestyle" to prevent the occurrence of metabolic syndrome.

\title{
Keywords
}

\author{
Metabolic Syndrome, Type 2 Diabetes, Abdominal Obesity, Nutritional and Metabolic Profile, \\ Physical-Activity
}

\section{Introduction}

Diabetes is one of the most common chronic diseases worldwide affecting nearly 200 million people, and is the fourth or fifth leading cause of death in the developed world [1] [2]. Each year, 3.2 million people around the world die from complications associated with diabetes. Type 2 diabetes, which accounts for 90 per cent of all diabetes, has become one of the major causes of premature illness and death, mainly through the increased risk of cardiovascular disease (CVD) which is responsible for up to 80 percent of these deaths [3] [4]. Several pathogenic processes are involved in the development of diabetes.

The association between obesity, type 2 diabetes, hypertension and several lipid anomalies is known since decades. It was proposed to regroup it in unique entity named metabolic syndrome [5]. MetS is characterized by insulin resistance related to an abnormal production of cytokines by adipocytes. It leads to an excess of plasma free fatty acids exert their toxicity especially in the liver and muscle level.

Metabolic syndrome is a pathology very frequent due especially to a modern life style with its excesses (unbalanced diet, inactivity). In Europe, the prevalence of metabolic syndrome is very high in the range of $10 \%-25 \%$ depending on sex and age [6]. Situation is even more worrying in the United States, where it is currently 26\% and more than half of Americans aged 60 years are affected [7]. In Algeria, the situation is worrying, since the last statistics show alarming results. The prevalence of MetS in Algeria is $26.33 \%$, indicating a national health survey which results are announced at the 2nd Congress of the Algerian Society of Vascular Medicine. The results of this survey in 16 Wilaya, based on a sample of 4.818 persons aged between 35 and 70 years old [8]. Another prospective study was conducted in 2008 in Tlemcen, a semi-urban town in northwestern Algeria, on a sample of 1088 subjects (612 women, $476 \mathrm{men}$ ), age $\geq 25$ years (mean age: 42.6 years), the rate of metabolic syndrome according to NCEP-ATP III is $17.4 \%$ [9].

The first official definition of the MetS appeared in 1999 by a working group of the World Health Organization (WHO) [10], followed by many other definitions, Working Group US National Cholesterol Education Program NCEP-ATP III [11], European Group for the Study of Insulin Resistance EGIR in 2002 [12], and finally, the American Association of Clinical Endocrinologists in 2003 [13].

However, different definitions are not only in the components proposed but also in the points defining each component. These divergences cause confusion.

To reduce this confusion, to standardize definitions and arrive at a consensus, the International Diabetes Federation (IDF) asked in 2005 to its working group on Epidemiology to gather experts from around the world (diabetes, cardiology, lipid, public health, epidemiology, genetics, metabolism, nutrition and public) to formulate a new worldwide definition of the metabolic syndrome [14].

However, these definitions, and the usefulness of the metabolic syndrome have been subject of many critical reviews from both European and American associations [15].

\section{Patients and Methods}

A cross-sectional survey was conducted in the western Algerian region (city of Sidi Bel Abbes) between (02/ 2009-03/2010) on a sample of 204 patients (SR = 1) which 15\% at Endocrinology department (University hospital of Dr. Abdelkader HASSANI) and 85\% at diabetology department (Guambeta Center).

Patients with metabolic syndrome are defined according to the criteria of the NCEP ATP III [11]. The study is detailed as follows: 


\subsection{Questionnaire}

The questionnaire survey is a monitoring tool to quantify and compare the information which was collected on a card on which are recorded the necessary information.

In this type of investigation, it was considered:

\subsubsection{Data Review}

$\checkmark$ Anthropometric measurements (weight, height, BMI, waist);

$\checkmark$ Blood pressure measured by a manual sphygmomanometer twice. The result given is the average of two measurements.

\subsubsection{Data Interrogation}

$\checkmark$ Age;

$\checkmark$ Sex;

$\checkmark$ Personal and family history;

$\checkmark$ The practice of physical activity.

\subsection{Food Consumption Survey}

Evaluation of food consumption consist to note in a card for three consecutive days, the nature and quantity of all foods ingested during this period, we took in considering the different meals of the day (breakfast, lunch, tea and dinner) without neglecting snacking between meals. We tried to get the maximum of precise information by using the usual culinary instruments (cup, bowl, plate, glass, spoon, etc.) information.

The conversion of food into different nutrients was realized by program (Nutrilog 1.41 software).

We took as a reference diet, the Mediterranean diet (Md), firstly because Algeria is part of the Mediterranean region and so there are common types of food and secondly because a lot of studies and surveys have demonstrated the value of this type of diet on the health level. The recommendations of the Adult Treatment Panel III for patients with metabolic syndrome are consistent with the general dietary recommendations [16]. The Scientific Steering Committee of the American Heart Association declared that a Mediterranean-style diet had a significant effect on the progression of cardiovascular disease [17]. The mortality statistics from databases of the World Health Organization show that for the period ranging from 1960 to 1990, the health of Mediterranean populations is positively influenced by comparison with those of northern Europe [18].

Many variants of the MD have been identified, but they have in common seven basic nutritional characteristics [18] [19]:

1) High ratio of mono-unsaturated fatty acids;

2) Moderate consumption of ethanol;

3) High consumption of vegetables;

4) High consumption of cereals (even in the form of bread);

5) High consumption of fruits;

6) Low consumption of meat and meat products;

7) Moderate consumption of milk and milk derivatives.

\subsection{Statistical Analysis}

The statistical analysis was conducted by program (Statistica version 4.1, Statsoft, Tulsa OK 4.1). Quantitative variables are expressed as mean values and standard deviation, while qualitative variables are expressed as the percentage; the quantitative results were compared by Student's t test. The significance level used was 0.05 .

\section{Results}

The pattern of the settlement studied by age bracket shows that $70.58 \%$ of the women have an age bracket ranging between 41 and 66 years whereas $85.29 \%$ of the men present an age bracket between 54 and 79 years.

The frequency of the metabolic syndrome is $86.27 \%$ whose predominance women which $(92.15 \%$ women vs $80.39 \%$ men). The age group most affected by the MetS among women and men is [54 - 79] years. We note 
also that $51.28 \%$ of men present three criteria of MetS, while $65.21 \%$ of women have four and five criteria (Table 1).

$\checkmark$ The results show that the criteria most dominant in men are hypertension and type 2 diabetes, whereas in women, the high waist is the most abundant criterion (Table 2).

$\checkmark$ Our population is in a state of overweight (BMI $\approx 29)$ whose women present an important percentage of $87.23 \%$ vs $71.95 \%$ men (Table 3 ).

$\checkmark$ According on student test, the differences are significant $(\mathrm{P}<0.05)$;

$\checkmark$ Obesity (BMI > 30) among women is 2.3 times higher than for men (Table 4).

$\checkmark$ Similarly, the frequency of visceral obesity is ( $95.74 \%$ women vs $59.75 \%$ men) and only $4.25 \%$ had normal waist versus $40.25 \%$ of men;

Moreover, the whole is underlined by a low physical activity with only $21.56 \%$ who practice it regularly (15.95\% women vs $28.04 \%$ men).

The estimate of food intake shows that:

$\checkmark$ The Carbohydrate intake is $60.97 \%$ among women compared to $60.54 \%$ in men whereas the complex carbohydrates represent (77\% among women vs $74 \%$ at men) of the total carbohydrates contribution;

$\checkmark$ Protein intake is $19.65 \%$ in women Vs. $19.43 \%$ in men represented mainly by vegetable protein (83.72\% for women Vs. $72.85 \%$ for men);

$\checkmark$ Lipids intake is caracterized by a lower consumption than the recommendation of the Mediterranean diet concerning the mono-unsaturated fatty acids (MUFA) which (39.44\% among women vs $40.24 \%$ at the men), as in poly unsaturated fatty-acids including(PUFA) (23.30\% among women vs $23.64 \%$ at the men) whereas an increase in the consumption of the saturated fatty-acids (SFA) is observed in the whole population including (37.24\% among women vs $36.10 \%$ at the men);

$\checkmark$ The consumption of water is insufficient with a daily contribution of $1.8 \mathrm{~L}$ among women against $1.7 \mathrm{~L}$ at the men; as for the consumed type of water, our results show that the majority of patients drink valve water which (84.78\% women vs. $70.51 \%$ men);

$\checkmark$ The daily intake of cholesterol in mg /day observed in patients with the metabolic syndrome is (266.44 mg among women vs. $262.60 \mathrm{mg}$ in men);

$\checkmark$ In the whole of the minerals salt intake, we note a higher consumption among women compared to men; (Table 5).

$\checkmark$ The daily consumption of dietary fibers is (23.53 mg among women vs. $23.35 \mathrm{mg}$ in men); (Table 6).

Table 1. Distribution of subjects according the number of criteria of MetS.

\begin{tabular}{lccc}
\hline & Women (\%) & Men (\%) & All Population (\%) \\
\hline 3 Criteria & 34.78 & 51.28 & 42.35 \\
4 Criteria & 41.3 & 37.17 & 39.41 \\
5 Criteria & 23.91 & 11.53 & 18.23 \\
\hline
\end{tabular}

Table 2. Distribution of different criteria of syndrome X.

\begin{tabular}{|c|c|c|c|}
\hline (NCEP ATP III) & Women (\%) & Men (\%) & Total Population (\%) \\
\hline Type 2 Diabetes and/or Hyperglycaemia & $81.91 \%$ & $98.78 \%$ & $89.77 \%$ \\
\hline Abdominal Obesity & $95.74 \%$ & $59.75 \%$ & $78.97 \%$ \\
\hline Hypertension & $82.97 \%$ & $92.68 \%$ & $87.50 \%$ \\
\hline Dyslipidemia & $69.14 \%$ & $75.60 \%$ & $72.15 \%$ \\
\hline
\end{tabular}

Table 3. Anthropometric parameters in both sexes.

\begin{tabular}{cccr}
\hline & Women & Men & Total Population \\
\hline BMI & $30.50 \pm 5.11$ & $27.10 \pm 3.57$ & $28.88 \pm 4.74$ \\
WAIST & $102.64 \pm 12.52$ & $96.93 \pm 9.53$ & $99.88 \pm 11.57$ \\
\hline
\end{tabular}


Table 4. Body mass index of patients with metabolic syndrome.

\begin{tabular}{cccc}
\hline BMI & Women & Men & Total Population \\
No. (\%) & No. (\%)
\end{tabular}

Table 5. Daily mineral intake expresses in mg per day.

\begin{tabular}{cccc}
\hline & Women & Men & MD \\
\hline Calcium & 662.40 & 561.71 & 900 \\
Potassium & 3315.74 & 3169.64 & 4700 \\
Magnesium & 351.92 & 325.79 & 420 \\
Phosphorus & 1560.41 & 1455.03 & 700 \\
Iron & 18.83 & 18.21 & 9 \\
Sodium & 4001.73 & 3562.90 & 1500 \\
\hline
\end{tabular}

Table 6. Daily fiber intake expresses in mg per day.

\begin{tabular}{cccc}
\hline & Women & Men & MD \\
\hline Fibers & 23.53 & 23.35 & 30 \\
\hline
\end{tabular}

\section{Discussion}

* Our study in the Wilaya of Sidi Bel Abbes is based on the evaluation of nutritional and metabolic characteristics among diabetic patients with metabolic syndrome; it provides alarming results that must be taken into consideration.

In our population we found a very important frequency of metabolic syndrome especially in women; they have a percentage $\approx 1.3$ times higher for those with four and five SM criteria.

Several studies show that the Metabolic Syndrome is more frequent among women.

$\checkmark$ The results show also that high waist is the most abundant criterion in women.

Generally associations between the components of MS are different according to the kind [20]:

- Among women: low HDL-cholesterol, high waist.

- At the men: hypertension.

$\checkmark$ The results of this study clearly show that obesity is a main actor of metabolic syndrome. Our population is in a state of overweight $(\mathrm{BMI} \approx 29)$.

Several studies showed that 'obesity represents the significant factor in the etiology of metabolic syndrome, contributing to the hyperglycemia, hypertension and the hypercholesterolemy [21].

$\checkmark$ Obesity (BMI > 30) in women is 2.3 times higher than in men.

Descriptive cross-sectional study on a representative sample of the population health sector Ain Taya (Blida) with 1511 individuals with age $\geq 20$ years were included. $25.9 \%$ of the population is obese (32.8\% women and $12.2 \%$ men). The prevalence of obesity among women was almost three times higher than men [22].

$\checkmark$ It show also that abdominal is very frequent in our population with 1.6 times higher among women than men with;

Abdominal obesity is considered as diagnostic and pathogenetic factor element of MetS [23].

The same study of Chibane and al shows that the prevalence of abdominal obesity was very high (53.5\%) of which $23.2 \%$ are men and $68.8 \%$ women. Abdominal obesity among women was significantly higher compared to men; [22]. 


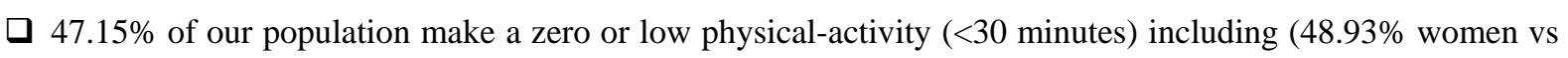
$48.78 \%$ men).

The physical-activity must be daily and adapted to the cardiorespiratory and articular capacities of each patient [24]. A minimum of 30 minute walks of intensity moderated per day is currently recommended and can naturally be associated with other types of physical activity and the most of our population don't practice it regularly.

$\square$ The estimate of food intake shows a qualitative imbalance.

$\checkmark$ The Carbohydrate intake is important compared to the Mediterranean Diet (MD).

Several studies show that it is recommended to push patients with diabetes type 2 in overweight to follow a Mediterranean diet depleted in carbohydrates [25].

$\checkmark$ An important qualitative protein imbalance is observed in our population including a vegetable protein intake $(\approx 1.4)$ times higher in women vs $(1.2)$ in men than the MD $(60 \%)$.

It is true that the Mediterranean diet recommends a low animal protein intake compared to vegetable proteins, but the contribution is very low in our population.

$\checkmark$ MD recommends a reduction of the saturated fatty-acids (25\%) and an increase in the monounsaturated fatty-acids $(50 \%)$ and our population present a contributions $(\approx 1.47)$ time higher in SFA and $(\approx 1.26)$ time less in MUFA compared to MD.

The intake of monounsaturated fatty acids is accompanied by an increase in the ratio of HDL to LDL cholesterol [26], decreased triglycerides and increased HDL-cholesterol [27]. These results indicate the beneficial effects of the consumption of monounsaturated fatty acids on the lipid profile in man.

$\checkmark$ The daily intake of cholesterol in mg/day observed is lower compared to MD (300 mg)

This can be explained by the restriction of foods of animal origin compared to vegetables foods.

$\checkmark$ The daily intake of calcium, potassium and magnesium are low compared to the recommendation of Mediterranean diet

In a five-year epidemiological study on more than 1000 healthy individuals, scientists have shown that a high intake of magnesium was associated with improved insulin sensitivity [28].

$\checkmark$ The daily sodium intake is higher than MD recommendations which we noted a rate (2.66 times among women vs 2.3 in men) higher;

Epidemiologic studies and clinical trials have demonstrated that a reduced intake of dietary sodium lowers blood pressure in both hypertensive and normotensive persons [29] [30].

$\checkmark$ The daily consumption of dietary fibers is low in both sexes compared to MD.

The use of fiber would affect glycemic regulation, reduce cholesterol, and may affect insulin resistance [31].

\section{Conclusions}

Those results ring the Alarm Bell, so we should be aware of the importance of the modulation of these risk factors through harmonization of "lifestyle" to prevent the occurrence of the metabolic syndrome which can provoke even other serious pathologies.

The prevention of the metabolic syndrome rests on three very important pillars:

Food diet: adapting a healthy diet rich in fiber and low in fat. Healthy eating reduces all the metabolic syndrome risk factors. It is simply recommended to reduce the caloric intake, restrict the consumption of saturated fatty acids, privilege on food with "low energy density", eat sufficient fruits and vegetables, etc., limit the salt consumption and increase the liquid contributions to reach a diuresis of two liters per day.

Physical activity: at least 30 to 60 minutes of exercise a day every day, if not five days a week. Physical activity allows a better use of glucose by the muscles. Moreover, regular practice helps to lose weight and especially to maintain a stable weight thereafter.

The psychic statute: psychic disturbances cause an important metabolic imbalance which it is recommended to take into account the psychic statute in the treatment and the prevention.

\section{Acknowledgements}

The authors thank all the personal of Endocrinology Department (University Hospital of Dr. Abdelkader HASSANI) and Diabetology Department (Guambeta Center). 


\section{Conflict of Interest and Funding}

The authors have not received any funding or benefits from industry or elsewhere to conduct this study.

\section{References}

[1] Wild, S., Roglic, G., Green, A., et al. (2004) Global Prevalence of Diabetes. Estimates for the Year 2000 and Projections for 2030. Diabetes Care, 27, 1047-1053. http://dx.doi.org/10.2337/diacare.27.5.1047

[2] World Health Organization (1994) Prevention of Diabetes Mellitus. Technical Report Series No. 844. WHO, Geneva.

[3] Diabetes Atlas. 2nd Edition, International Diabetes Federation, 2003.

[4] UKPDS Group (1996) UK Prospective Diabetes Study 17: A Nine-Year Update of a Randomized, Controlled Trial on the Effect of Improved Metabolic Control on Complications in Non-Insulin-Dependent Diabetes Mellitus. Annals of Internal Medicine, 124, 136-145. http://dx.doi.org/10.7326/0003-4819-124-1 Part 2-199601011-00011

[5] Ferrannini, E., Haffner, S.M. and Mitchell, B.D. (1991) Hyperinsulinaemia: The Key Feature of a Cardiovascular and Metabolic Syndrome. Diabetologia, 34, 416-422. http://dx.doi.org/10.1007/BF00403180

[6] Balkau, B., Vernay, M., Mhamdi, L., Novak, M., Arondel, D., Vol, S., et al. (2003) The Incidence and Persistence of the NCEP (National Cholesterol Education Program) Metabolic Syndrome. The French D.E.S.I.R. Study. Diabetes \& Metabolism, 29, 526-532. http://dx.doi.org/10.1016/S1262-3636(07)70067-8

[7] Zimmet, P., Shaw, J. and Alberti, K.G.M.M. (2003) Preventing Type 2 Diabetes and the Dysmetabolic Syndrome in the Real World: A Realistic View. Diabetic Medicine, 20, 693-702. http://dx.doi.org/10.1046/j.1464-5491.2003.01052.x

[8] Atek, M., Laid, Y., Mézimèche, N., Boutekdjiret, L., Lebcir, N., Oudjehane, R., Maire, B. and Eymard-Duvernay, S. (2008) Syndrome métabolique en Algérie: Caractéristiques épidémiologiques. Données de l’Enquête Nationale Santé. (CO) 2ème Congrès National de la Société Algérienne de Médecine Vasculaire (SAMEV). 1er et 2 mars, Alger (Algérie).

[9] Yahia-Berrouiguet, A., Benyoucef, M., Meguenni, K. and Brouri, M. (2009) Enquête sur la prévalence des facteurs de risque de maladies cardiovasculaires à Tlemcen (Algérie). Médecine des Maladies Métaboliques, 3, 313-319.

[10] World Health Organization. Definition. Diagnosis and 3 World Health Organization (1999) Definition, Diagnosis and Classification of Diabetes Mellitus and Its Complications. Classification of Diabetes Mellitus and Its Complications. Report of a WHO Consultation.

[11] (2001) Third Report of the Expert Panel on Detection, Evaluation, and Treatment of High Blood Cholesterol in Adults (Adult Treatment Panel III), National Heart, Lung, and Blood Institute, National Institutes of Health. National Cholesterol Education Program.

[12] European Group for the Study of Insulin Resistance (EGIR) (2002) Frequency of the WHO Metabolic Syndrome in European Cohorts, and an Alternative Definition of an Insulin Resistance Syndrome. Diabetes \& Metabolism, 28, 364376.

[13] ACE Position Statement (2003) ACE Guideline for Glycemic Control. Endocrine Practice, 9, 19.

[14] International Diabetes Federation (2005) The IDF Consensus Worldwide Definition of the Metabolic Syndrome [Article Online]. https://www.idf.org/webdata/docs/MetS_def_update2006.pdf

[15] Kahn, R., Buse, J., Ferrannini, E., Stern, M., American Diabetes Association, European Association for the Study of Diabetes (2005) The Metabolic Syndrome: Time for a Critical Appraisal: Joint Statement from the American Diabetes Association and the European Association for the Study of Diabetes. Diabetes Care, 28, 2289-304. http://dx.doi.org/10.2337/diacare.28.9.2289

[16] Krauss, R.M., Eckel, R.H., Howard, B., Appel, L.J., Daniel, S.R., Deckelbaum, R.J., et al. (2000) AHA Dietary Guidelines: Revision 2000: A Statement for Healthcare Professionals from the Nutrition Committee of the American Heart Association. Circulation, 102, 2284-2299. http://dx.doi.org/10.1161/01.CIR.102.18.2284

[17] Robertson, R.M. and Smaha, L. (2001) Can a Mediterranean Style Diet Reduce Heart Disease? Circulation, 103, 18211822. http://dx.doi.org/10.1161/01.CIR.103.13.1821

[18] Trichopoulou, A. and Vasilopoulou, E. (2000) Mediterranean Diet and Longevity. British Journal of Nutrition, 84, S205-S209. http://dx.doi.org/10.1079/096582197388554

[19] Goulet, J., Lamarche, B. and Nadeau G.S. (2003) Effect of a Nutritional Intervention Promoting the Mediterranean Food Pattern on Plasma Lipids, Lipoproteins Body Weight in Healthy French-Canadian Women. Atherosclerosis, 170, 115-124. http://dx.doi.org/10.1016/S0021-9150(03)00243-0

[20] Dallongeville, J., Cottel, D., Arveiler, D., Tauber, J.P., Bingham, A., Wagner, A., Fauvel, J., Ferrières, J., Ducimetière, P. and Amouyel, P. (2004) The Association of Metabolic Disorders with the Metabolic Syndrome Is Different in Men 
and Women. Service d’Epidémiologie et de Santé Publique, INSERM U 508, Institut Pasteur de Lille, Lille, France. Annals of Nutrition and Metabolism, 48, 43-50. http://dx.doi.org/10.1159/000075304

[21] Standl, E. (2005) Aetiology and Consequences of the Metabolic Syndrome. European Heart Journal, 7, D10-D13. http://dx.doi.org/10.1093/eurheartj/sui023

[22] Chibane, M., Attif, L., Makhlouf, L., Lanasri, N. and Biad, A. (2008) Prévalence de l’obésité dans un secteur sanitaire de l'Algérois. Diabetes \& Metabolism, 34, H74-H75. http://dx.doi.org/10.1016/s1262-3636(08)73023-4

[23] Bray, G.A. and Champagne, C.M. (2004) Obesity and the Metabolic Syndrome: Implications for Dietetics Practitioners. Journal of the American Dietetic Association, 104, 86-89. http://dx.doi.org/10.1016/j.jada.2003.10.041

[24] Sigal, R.J., Kenny, G.P., Wasserman, D.H. and Castaneda-Sceppa, C. (2004) Physical Activity/Exercise and Type 2 Diabetes. Diabetes Care, 27, 2518-2539. http://dx.doi.org/10.2337/diacare.27.10.2518

[25] Elhayany, A., Lustman, A., Abel, R., Attal-Singer, J. and Vinker, S. (2010) A Low Carbohydrate Mediterranean Diet Improves Cardiovascular Risk Factors and Diabetes Control among Overweight Patients with Type 2 Diabetes Mellitus: A 1-Year Prospective Randomized Intervention Study. Diabetes, Obesity and Metabolism, 12, 204-209. http://dx.doi.org/10.1111/j.1463-1326.2009.01151.x

[26] Mensink, R.P. and Katan, M.B. (1992) Effect of Dietary Fatty Acids on Serum Lipids and Lipoproteins. A MetaAnalysis of 27 Trials. Arteriosclerosis and Thrombosis, 12, 911-919. http://dx.doi.org/10.1161/01.ATV.12.8.911

[27] Garg, A. (1998) Treatment of Diabetic Dyslipidemia. American Journal of Cardiology, 81, 47B-51B. http://dx.doi.org/10.1016/S0002-9149(98)00038-1

[28] Ma, B., Lawson, A.B., Liese, A.D., Bell, R.A. and Mayer-Davis, E.J. (2006) Dairy, Magnesium, and Calcium Intake in Relation to Insulin Sensitivity: Approaches to Modeling a Dose-Dependent Association. American Journal of Epidemiology, 164, 449-458. http://dx.doi.org/10.1093/aje/kwj246

[29] Whelton, P.K., He, J., Appel, L.J., Cutler, J.A., Havas, S., Kotchen, T.A., et al. (2002) Primary Prevention of Hypertension. Clinical and Public Health Advisory from the National High Blood Pressure Education Program. Journal of the American Medical Association, 288, 1882-1888. http://dx.doi.org/10.1001/jama.288.15.1882

[30] Chobanian, A.V., Bakris, G.L., Black, H.R., Cushman, W.C., Green, L.A., Izzo Jr., J.L., et al. (2003) The Seventh Report of the Joint National Committee on Prevention, Detection, Evaluation, and Treatment of High Blood Pressure: The JNC 7 Report. Journal of the American Medical Association, 289, 2560-2572. http://dx.doi.org/10.1001/jama.289.19.2560

[31] Traxer, O., Lechevallier, E., Saussine, C., Daudon, M. and Haymann, J.P. (2008) Syndrome métabolique et lithiase urinaire. Une notion nouvelle pour l'urologue. Progrès en Urologie, 18, 832-836. http://dx.doi.org/10.1016/j.purol.2008.09.036 